\title{
Hermenéutica analógica y teología de la liberación*
}

\section{Mauricio Beuchot**}

Recibido: 1 de octubre de 2012 • Aprobado: 15 de diciembre de 2012

\section{Resumen}

El artículo trata, dentro del ámbito de la teología, sobre la hermenéutica tal como puede ser aplicada a ella. Se centra sólo en una de sus aplicaciones, pero suficientemente amplia: la teología de la liberación latinoamericana. Además, trata de hacer ver que se deja un lugar importante no sólo para la hermenéutica, sino también para la analogía, esto es, para una hermenéutica analógica.

Primero relaciona la hermenéutica con la teología, mostrando el porqué del giro hermenéutico en la teología católica reciente. Después se ocupa de mostrar la utilización de la hermenéutica en el caso de la teología de la liberación. Finalmente, aboga por la pertinencia, en el futuro, de una hermenéutica analógica para el quehacer teológico. Ciertamente han cambiado las condiciones que dieron lugar a la teología de la liberación, que fue muy hermenéutica, pero siguen vigentes las condiciones que nos hacen aplicar la hermenéutica a la teología, concretamente una hermenéutica analógica.

Palabras clave: hermenéutica, analogía, teología, liberación.

* Este es un producto de la investigación del autor.

* Doctor en Filosofía de la Universidad Iberoamericana (UIA) con la tesis: "Sobre el problema de los universales en la filosofía analítica y en la metafísica tomista". Cursó, estudios de historia del pensamiento, filosofía aristotélica y medieval, en la Universidad de Friburgo, Suiza. Investigador del Instituto de Investigaciones Filológicas (IIFL) de la UNAM, miembro de la Academia Mexicana de la Historia, miembro de número en la Academia Mexicana de la Lengua y miembro de la Academia Pontificia de Santo Tomás de Aquino. Actualmente es coordinador del Seminario de Hermenéutica del Instituto de Investigaciones Filológicas de la Universidad Nacional Autónoma de México (UNAM). Correo electrónico: mbeuchot50@gmail. com. 


\title{
Analogical hermeneutics and liberation theology
}

\begin{abstract}
The article is about, within the scope of theology, hermeneutics as can be applied to it. It focuses only in one of its applications, but wide enough; the Latin American liberation theology. Also, it tries to show that it leaves a significant place not only for hermeneutics, but also for analogy, this is, for an analogical hermeneutics.

First it connects hermeneutics with theology, showing why of the hermeneutic shift in recent catholic theology. Afterwards it addresses showing the use of hermeneutics in liberation theology. And, finally, it advocates for the appropriateness, in the future, of an analogical hermeneutics for the theological task. Certainly conditions that gave rise to the liberation theology have changed, which was very hermeneutical, but conditions that make us apply hermeneutics to theology, and specifically an analogical hermeneutics, are still in force.
\end{abstract}

Keywords: Hermeneutics, analogy, theology, liberation.

\section{Introducción}

Dentro del contexto de la teología, hablaré en estas páginas de la hermenéutica tal como puede ser aplicada a ella. Me enfocaré sólo en una de sus aplicaciones, pero de manera amplia, la de la teología de la liberación latinoamericana. También trataré de hacer ver que se deja un lugar importante tanto para la hermenéutica, como para la analogía, es decir, para una hermenéutica analógica.

Primero intentaré relacionar la hermenéutica con la teología, con lo cual espero que se revele el porqué del giro hermenéutico en la teología católica reciente. Después me ocuparé de hacer ver cuál es la utilización de la hermenéutica en el caso de la teología de la liberación. Y, por último, abogaré por la pertinencia, en el futuro, de una hermenéutica analógica para el quehacer teológico. Ciertamente han cambiado las condiciones que dieron lugar a la teología de la liberación, que fue muy hermenéutica, pero aún se encuentran vigentes las condiciones que nos hacen aplicar la hermenéutica a la teología, concretamente una hermenéutica analógica. 


\section{Hermenéutica y teología}

La hermenéutica ocupa un lugar importante e imprescindible en la labor teológica, pues es la disciplina de la interpretación de textos, por ello, permite comprenderlos críticamente (Beuchot, 2011). La hermenéutica es un instrumento de comprensión, entendida aquí como un proceso por medio del cual se va profundizando continuamente.

Heidegger veía la actividad hermenéutica como un existenciario del hombre, esto es, como una cualidad esencial que ejerce el ser humano por el mismo hecho de existir. Su discípulo Gadamer, comparó la actividad interpretativa con la phrónesis o prudencia aristotélica, porque siempre supone un contexto, e interpretar es poner un texto en su contexto, a la luz del cual cobra sentido. Y Michel Foucault añadió el aspecto crítico, que tiene que darse desde el momento en que el acto interpretativo lleva a un juicio, y juzgar es criticar, pero sobre todo, Foucault alude a que al interpretar criticamos nuestra situación histórico-cultural. Paul Ricoeur dio un lugar relevante a la interpretación de símbolos religiosos, y le asignó un uso destacado de la analogía, del concepto de analogía que atraviesa la historia.

En el campo de la teología, uno de los que otorgó relevancia a la hermenéutica, fue el dominico Eduard Schillebeeckx (Chamoso, 1982). No solamente al uso de la hermenéutica, sino a una actitud hermenéutica en el quehacer del teólogo. Schillebeeckx fue pionero en esto, tenía muy claro que el teólogo es un intérprete, en doble sentido: ayudar a comprender y ayudar a transmitir algo, en este caso, el mensaje revelado.

Por eso el teólogo debía conocer la cultura de su época, porque tenía que hablar a los hombres de su momento, para hacerles comprensible la palabra de Dios. De hecho, el hermeneuta era originalmente el traductor, el que hacía entendible y comunicaba el mensaje. Del mismo modo, el teólogo es un hermeneuta de profesión, pues se dedica a estudiar la Sagrada Escritura, pero para darla a conocer a los hombres de su tiempo y a que sea comprendida por ellos. De ahí que deba estar empapado de la cultura de su época, sobre todo de la filosofía.

Asimismo, en la teología de la liberación se cultivó la hermenéutica. Esto se ve con dos autores muy connotados: Juan Carlos Scannone y Enrique Dussel. (Dussel, 1992) (Scannone, 2003). Además, en ambos se nota un uso destacado del concepto de analogía, tan presente en la tradición teológica del catolicismo. Lo usaban en forma de analéctica, esto es, una forma dialectizada de la analogía.

Veamos algunos de los rasgos más sobresalientes de la teología de la liberación. Suele asignarse como el pionero a Gustavo Gutiérrez, quien después del 
Concilio Vaticano II y de la reunión de Medellín, Colombia, supo reflejar la situación de opresión de América Latina y proponer una teología de la liberación. Hubo cultivadores muy distinguidos como Hugo Assman, Franz Hinkelammert, Ignacio Ellacuría, Leonardo Boff, y otros. A continuación enunciaré algunos de los aspectos más generales de dicho movimiento.

Y es que la teología de la liberación fue un fenómeno muy indicativo de los procesos eclesiásticos, sobre todo de cambio. Por eso, más que hablar de sus exponentes principales, los teólogos de la liberación, que recogieron sus aspectos teóricos desde la praxis del pueblo, es preciso verlo como un movimiento que responde a la situación concreta del momento. Inclusive puede decirse que en varios aspectos sigue vigente, pues, aunque han cambiado los elementos culturales y sociales, no ha acabado la opresión ni se ha desterrado la pobreza. Ahora estamos en lo que se llama la globalización, y los teóricos de la liberación hablan de que sea incluyente, que extienda sus beneficios a todos, pues muchos siguen marginados de ella.

A pesar de que los teóricos de la teología de la liberación han adoptado diferentes metodologías o mediaciones, por ejemplo la pragmática de Apel y Habermas, siguen comprometidos en la crítica de la opresión, tanto económica como cultural, por ejemplo en la línea del poscolonialismo. Hay mucho trabajo aún para la hermenéutica, ya que ella es indispensable para interpretar la situación de nuestro momento, el curso que van tomando los acontecimientos, hacia dónde apuntan, de manera profética, y qué reflexión desde la fe puede ofrecérseles para participar y colaborar en la praxis cristiana actual.

\section{Sobre la teología de la liberación}

Ya en el ámbito concreto de la aplicación de la hermenéutica a la teología de la liberación, a saber, a los fenómenos religiosos que influyen en la liberación sociopolítica, contamos con un libro muy ilustrativo de Luis Gerardo Díaz Núñez, que se polariza hacia ese fenómeno religioso tan importante en nuestros países: la teología de la liberación (Núñez, 2009). El libro resulta una guía muy útil y provechosa para el tema, tan importante, de la utopía y la liberación en América Latina. Por eso lo seguiremos, para destacar los elementos más salientes de este fenómeno religioso de la teología de la liberación.

El libro comienza diciendo que la teología de la liberación fue una propuesta del pensamiento latinoamericano que se estaba necesitando y deseando en su momento. En efecto, el movimiento de la filosofía y la teología de la liberación ha sido muy relevante para nuestra historia, y aun cuando ha suscitado muchas 
investigaciones, no deja de presentar aspectos, por lo que debe seguir siendo estudiado.

Algo que resulta muy interesante en esta obra, es que conecta el pensamiento religioso con el pensamiento latinoamericano. Conexión que algunos evitan, o recelan, pero que de ninguna forma se puede negar; antes bien, tiene que abordarse con la profundidad que merece. Es algo que ha estado muy presente en nuestra historia, se trata de la teología de la liberación y de la utopía cristiana pensada para nuestros países.

No solamente veo en el trabajo de Díaz Núñez el mérito de historiar esos acontecimientos tan importantes para nosotros, sino también el esfuerzo por reflexionar, a partir de ellos, sobre el fenómeno de la posmodernidad en nuestros ámbitos. Tiene, pues, un aspecto propositivo muy interesante y que descuella en el conjunto de los estudios de esta naturaleza.

El aspecto de la posmodernidad que se toca es, por supuesto, el de la globalización, que implica un recrudecimiento del liberalismo o capitalismo, en forma de neoliberalismo o neocapitalismo, que solamente se distingue del anterior en que es más radical (Núñez, 2009). La presencia casi omnímoda de la globalización, nos obliga a reflexionar para buscar la respuesta que podemos dar a esta situación tan preocupante.

Luis Gerardo Díaz Núñez aborda el tema de la teología de la liberación, usando como instrumento conceptual la hermenéutica analógica, que es una propuesta mexicana y latinoamericana, y que se está mostrando como útil para acompañar los estudios sobre pensamiento latinoamericano. Un ejemplo es el mismo libro que él nos está entregando.

Su seriedad se ve en todo el aparato sociológico y económico, que se despliega para situar los movimientos de pensamiento que se presentan, lo cual es sumamente hermenéutico, pues es dotarlos con su contexto para comprenderlos mejor.

La teología de la liberación fue un despliegue de la historia reciente de la religiosidad en nuestro ámbito. Con ello se ve mejor la presencia tan fuerte que ha tenido la religión en nuestros países latinoamericanos, la cual ha moldeado en gran medida los acontecimientos y los movimientos intelectuales que los han acompañado.

Pero tal vez, el tema nuclear, es el de la teología de la liberación como sostenedora de una utopía en América Latina (Núñez, 2009). Es el ideal de emancipación, pero no sólo de eso, sino además, de realización de las personas en una vertiente cristiana. Es decir, este movimiento supo conjuntar tanto la base de justicia como el ideal de vida, o de vida buena, que es el que precisamente da sentido al anterior. 
No se dio únicamente el movimiento de la teología de la liberación, sino que a él se añadieron otros movimientos que lo han promovido o acompañado, como la teología feminista, la teología de color, etc. Todos esos son fenómenos importantes en este tiempo de la tarda modernidad o posmodernidad.

Lo que resulta más importante de la teología de la liberación, es que nos deja abierta una reflexión sobre la situación presente de América Latina en la posmodernidad. Alguno dirá que no tenemos posmodernidad porque tampoco tuvimos modernidad. Pero ahora la posmodernidad se impone y se extiende, al menos en esa forma de globalización. Lleva como cortejo muchas injusticias (algunos críticos dicen que lo único que ha globalizado es la pobreza), la cual no cesa de mostrarse amenazante.

Es importante conocer la historia de la teología de la liberación (Maccise, 1987), pero más lo es, reflexionar sobre los acontecimientos reales que nos cuestionan de manera acuciante. No podemos soslayarlos ni dejarlos sin respuesta, por lo menos tenemos que intentar responderlos en alguna medida. Es nuestra obligación como pensadores y latinoamericanos.

En ese sentido, el libro que presento me parece una aportación excelente para lo que estamos construyendo como pensamiento de América Latina. El libro de Díaz Núñez arroja mucha luz sobre ese movimiento de la teología de la liberación, cuyos alcances no podemos todavía acotar ni valorar adecuadamente. Es un intento de colaborar a esa tarea que tenemos aún pendiente. Nos mueve a la meditación comprometida sobre los problemas actuales.

\section{Hermenéutica analógica y teología}

He dicho que la hermenéutica ha sido aplicada a la teología, sin embargo, cabe aclarar que en la actualidad la hermenéutica se debate entre las corrientes unívocas y las corrientes equívocas. Las primeras, como las del positivismo, pretenden una interpretación totalmente clara, distinta, rigurosa y exacta. Eso no pasa de ser un ideal, ya que en la interpretación siempre interviene nuestra subjetividad, nuestra cultura, nuestro contexto histórico, etc., lo cual hace que no se pueda pensar en una objetividad a toda prueba, como la que plantea el objetivismo de los positivistas. Pero ahora predominan las hermenéuticas equívocas, las cuales descreen de toda objetividad y desesperan de alcanzar una interpretación más o menos objetiva, hundiéndose en el mar de la ambigüedad y la oscuridad, en un relativismo extremo. Son las hermenéuticas de muchos posmodernos. 
Por eso hace falta una hermenéutica analógica, ya que la analogía está intermedia entre la univocidad y la equivocidad (Beuchot, 2009). No pretende la claridad y distinción de la hermenéutica unívoca, pero tampoco se derrumba en la oscuridad y confusión de la hermenéutica equívoca. La univocidad hoy en día, se ve en el absolutismo objetivista de algunos sucesores del positivismo. La equivocidad se capta en el relativismo extremo de muchos posmodernos. En cambio, la analogicidad acepta un relativismo moderado, pero no deja de tener una tendencia hacia la objetividad, en la medida en que sea alcanzable en las ciencias humanas y sociales, que es donde más se utiliza la hermenéutica.

La hermenéutica analógica ya ha encontrado aplicaciones a la teología, tanto en la bíblica (Reyes, 2009) como en la sistemática (Beuchot, 2008), ha abierto caminos fructíferos en ella. Inclusive he encontrado algunas hermenéuticas llamadas "analógicas", que no conocía cuando lancé mi propuesta, y me parece que ellas responden a una necesidad de la teología del momento. La misma noción de analogía fue utilizada en la teología de la liberación, por eso pasaré a señalar algunos contactos de esa corriente teológica con la hermenéutica analógica.

La hermenéutica analógica se ha mostrado, pues, como un instrumento útil para la reflexión teológica. De hecho ya ha habido una gran tradición de utilización de la analogía en el quehacer teológico; en todas las épocas la teología ha tenido un papel hermenéutico, pero mucho más ahora, por eso en la actualidad es cuando más parece que pueden embonar la teología y una hermenéutica analógica. Seguirá siendo una teología analógica, como en esa larga tradición, pero además, profundizará su estatuto hermenéutico, sin caer en los extremos del univocismo y el equivocismo.

Una hermenéutica unívoca daña a la teología, endureciéndola con su formalismo frente a la experiencia viva que trata de recoger y transmitir, y una hermenéutica equívoca priva de formas a esa experiencia hasta el punto en que se volatiliza; en cambio, una hermenéutica analógica da cauces formales a esa experiencia, sin pretender anquilosarla, le da la flexibilidad necesaria para que tenga coherencia y vida al mismo tiempo.

Sobre todo, una hermenéutica hará que la teología, tome en cuenta la analogía con la que puede aplicar el mensaje revelado a nuestro tiempo (y la noción de aplicación es fundamental en la hermenéutica, para Gadamer). Solo analógicamente se recoge la historia, solo analógicamente se reproduce. Hay que atender a la novedad del momento, de la circunstancia o del kairós, que es lo que toma en cuenta la prudencia o phrónesis, la cual tiene un lugar eminente en la hermenéutica analógica, precisamente por ser analogicidad o proporción. Se trata de aplicar, 
proporcionalmente, el mensaje revelado a las diversas épocas y a las diversas culturas en las que ha de encarnarse.

Por eso hubo aplicaciones necesarias al estado del mundo en su momento, como la teología de las realidades terrestres, la teología política, y la teología de la liberación. Ahora han cambiado las circunstancias, pero han permanecido de manera análoga los problemas; por ejemplo, la globalización ha cambiado la faz del mundo en cuanto a la economía y la política, pero la pobreza no ha sido erradicada, ni la injusticia, ni la opresión. Así pues, hay que tomar en cuenta el esfuerzo de responder a esa situación con la teología de la liberación, que es en la que nos centraremos a continuación.

\section{Teología de la liberación y hermenéutica analógica}

En cuanto a la utilización del concepto de analogía en la teología de la liberación, tenemos el caso ilustrativo de Juan Carlos Scannone y Enrique Dussel. Ambos echaron mano de la propuesta de Bernhart Lakebrink, la analéctica, resultado de su reflexión sobre la relación de la analogía tomista y la dialéctica hegeliana (Lakebrink, 1967) Era una forma de dinamizar la analogía, para que ayudara a comprender los procesos vivos de la historia.

Scannone se ha abierto en gran medida a la hermenéutica analógica, y la toma en cuenta en trabajos suyos. Allí puede uno encontrar que la analogía sigue siendo la base de la analéctica. Ciertamente conviene dialectizar la analogía, para dinamizarla y que tenga un papel más activo en el seguimiento de los procesos de la realidad, en este caso de la realidad social.

Pero en la analogía yo encuentro una dialéctica distinta de la que me parece que proponen Scannone y Dussel, si los he entendido bien. Ellos, en seguimiento de Lakebrink, adoptan una dialéctica hegeliana, o hegeliano-marxista, para la analéctica y la ana-dialéctica. En cambio, me da la impresión de que la analogía esconde en su entraña una dialéctica diferente (Dussel, 1982) (Dussel) (Scannone, 1999) (Scannone, 2005) Es una dialéctica que, a diferencia de la de Hegel, no tiene síntesis, no llega a una reabsorción y superación de los opuestos, sino que los deja coexistir, no los destruye, sino que los conserva con sus características antitéticas, pero conviviendo y trabajando el uno para el otro (Beuchot, 2008a) (Beuchot, 2009)

Es la auténtica idea de dialéctica de Heráclito, lo cual se ve en los ejemplos que proponía, como el fuego y el leño, o sobre todo el arco y la lira. El fuego quema el leño, pero si el leño se acaba, se extingue el fuego, el arco se opone a la 
lira, pero entre ambos sacan una melodía, trabajan el uno para el otro. Hay que aprovechar el conflicto.

Ésta es también la dialéctica inconclusa y abierta de Eckhart, Nicolás de Cusa y muchos renacentistas y barrocos. Es, igualmente, la dialéctica trágica de Hölderlin, Kierkegaard, Nietzsche y Freud, es decir, una dialéctica que no suprime las diferencias ni las oposiciones, sino que las aprovecha. En Hölderlin fue la dialéctica de la tragedia; en Kierkegaard fue la dialéctica de la paradoja; en Nietzsche fue dialéctica trágica, como la que se da entre Apolo y Dioniso, que no llegan a ninguna síntesis, no engendran nada nuevo, pero colaboran para que de su interacción surja la filosofía trágica, a la que invitaba Nietzsche en El origen de la tragedia. En Freud es la dialéctica o interacción que se da en su metapsicología, donde en el aparato psíquico, de acuerdo al segundo modelo, el ello y el superyó distienden al yo y lo angustian, pero éste puede negociar con ellos y obtener un equilibrio pulsional.

Así pues, la hermenéutica analógica tiene ciertamente su dialéctica, pero es diferente, precisamente la dialéctica de la diferencia. Por eso Gilles Deleuze negaba que hubiera dialéctica en Nietzsche, decía que la rechazaba en aras de la diferencia, para evitar que la dialéctica homogeneizara los opuestos, las diferencias, y preservara la diferencia, la cual tanto interesaba al pensador francés posmoderno (Deleuze, 1969) Pero lo que no vio Deleuze fue que Nietzsche tenía esa dialéctica diferente, auténticamente de la diferencia.

Eso puede ayudarnos a repensar la teología de la liberación en la línea de la analéctica, pero con una dialéctica analógica diferente, no como la hegeliana, sino más abierta, que use la analogía para no destruir, para no negar las diferencias, para no anular los opuestos, sino conservarlos pero en tensión, y en ella, que constituirá el tercer elemento dialéctico, se dará una coexistencia que a la postre será no solamente pacífica, sino benefactora, pues los opuestos trabajarán el uno para el otro, que es lo que se desea en una sociedad.

Asimismo, la analogía está en el núcleo de la justicia, es su modelo. La analogía de proporción, lo es de la justicia conmutativa y de la legal, pues a cada quien se le debe su porción, su derecho. Y la analogía de atribución corresponde a la justicia distributiva, pues atiende a necesidades y méritos, y toma en cuenta las diferencias para establecer una jerarquía, en la que el gobernante sea el analogado principal, no un déspota unívoco, y los gobernados sean analogados secundarios, en orden descendente, de modo que se dé un orden jerárquico en la sociedad.

La liberación quiere restablecer la justicia, por eso una teología de la liberación ha de buscar la justicia. Y la justicia tiene el modelo de la analogía, tanto de 
la de proporción como de la de atribución. Junta las dos, y con ello logra el equilibrio, la igualdad, la equidad y la armonía en la sociedad. Su vehículo es la hermenéutica analógica, porque ella nos hace interpretar al hombre y a la sociedad, para ver qué derechos son los que le competen y cómo los debemos salvaguardar.

Por eso la hermenéutica analógica ayuda en la reflexión de la teología, concretamente lo hace con la de la liberación, como apoya en el estudio de la ética y la filosofía política, sobre todo incorporando a la religión. Nos hace interpretar y reinterpretar, tratar de comprender al ser humano, para darle una ética, un derecho y una filosofía política que sean acordes con sus necesidades y sus legítimos deseos o aspiraciones. De otra manera solamente se liberará de momento, no radicalmente; no sabremos hacia dónde llevamos al ser humano, a qué liberación lo estamos conduciendo. Tal es la labor de la filosofía y la teología, ser conciencia del ser humano, tanto al nivel individual como al nivel colectivo. Por eso tenemos que recuperar ese papel que han tenido, y que a veces no manifiestan de modo tan claro.

\section{Conclusión}

Para apreciar las posibilidades de la hermenéutica en nuestro estudio de la teología de la liberación, hemos visto algunos ejemplos de esa utilización de la teoría de la interpretación en el ámbito religioso. Hemos elegido algunos, que a nuestro parecer, son los más cercanos al tema y, por ende, los más ilustrativos. Uno corresponde a la analéctica de Scannone y Dussel; otro, a la utilización que ha hecho de la hermenéutica analógica. para la teología de la liberación. Luis Gerardo Díaz Núñez. Y es que esa teología tiene una hermenéutica peculiar, desde la perspectiva de la búsqueda de la justicia.

En todo caso, la hermenéutica encuentra presencias insospechadas. Del mismo modo se aplica a la teología de la liberación a través de la filosofía de la religión. Aquí hemos visto cómo se da en la teología de la liberación a través de la dialéctica. Y todo ello, nos convence de las posibilidades de una aplicación fructífera de la hermenéutica analógica al estudio de la teología, tal como lo manifiesta la aplicación que se ha hecho a la teología de la liberación, que es lo que ahora hemos intentado.

Así pues, una hermenéutica analógica puede tener buenos resultados si se aplica a la teología. En el caso de la teología de la liberación latinoamericana, muestra su fecundidad, porque muchos de los ideales que ésta tuvo en años pasados parecen haberse olvidado; devorados como estamos por esta globalización 
que todo lo inunda. No se han resuelto los problemas de la pobreza, de la opresión ni de la injusticia. Hay que seguir luchando por un mundo más justo, y eso nos hace recuperar algunas de esas búsquedas, tal vez ya no con los esquemas anteriores, pero sí con los mismos ideales. Los ideales son símbolos, y los símbolos son los que nos hacen vivir.

\section{Referencias}

Beuchot, M. (2008). Hermenéutica analógico-icónica y teología. (P. U. Facultad de Teología, Ed.) Col. Teología hoy(67).

Beuchot, M. (2008a). Sobre la dialectización de la analogía. (Respuesta a Ortiz-Osés). Analogía filosófica(XXII/1), 191 ss.

Beuchot, M. (2009). Hermenéutica, analogía y dialéctica para América Latina. Stromata, $\operatorname{LXV}(1 / 2), 75$ ss.

Beuchot, M. (2009). Tratado de hermenéutica analógica. Hacia un nuevo modelo de interpretación. México: UNAM-Ítaca.

Beuchot, M. (2009a). Tratado de hermenéutica analógica. Hacia un nuevo modelo de interpretación. (Cuarta ed.). México: UNAM-Ítaca.

Beuchot, M. (2011). Perfiles esenciales de la hermenéutica. México: FCE.

Chamoso, R. S. (1982). La teoría hermenéutica de E. Schillebeeckx. Principios y criterios para la actualización de la tradición cristiana. Salamanca: Universidad Pontificia de Salamanca.

Deleuze, G. (1969). Nietzsche y la dialéctica. Eco, XIX(5-7 ), 605 ss.

Dussel, E. (1982). Pensée analectique en philosophie de la libération. En P. G. Secretan, Analogie et dialectique. Essais de théologie fondamentale (pág. 93 ss). Genève: Labor et Fides.

Dussel, E. (1992). Hermenéutica y liberación. Fe la 'fenomenología hermenéutica' a una 'filosofía de la liberación' (diálogo con Paul Ricoeur). 1, 141 ss.

Dussel, E. (s.f.). La analogía de la palabra (el método analéctico y la filosofía latinoamericana). En E. Dussel, nalogía Filosófica (pág. 29 ss).

Lakebrink, B. (1967). Hegels dialektische Ontologie und die thomistische Analektik. Freiburg i.B.: Rombach.

Maccise, C. (1987). La teología de la liberación. 20 años de una praxis y reflexión teológicopastoral. México: CEHVAC.

Núñez, L. G. (2009). Utopía y liberación en América Latina. La teología de la liberación. Desarrollos recientes (el desafío globalizador y posmoderno). México: UNAM. 
Reyes, G. (2009). Hermenéutica y analogía: hacia una epistemología analógica del texto narrativo biblíco. En R. B. Beledo, Hermenéutica analógica y crítica filosófica (pág. 7 ss). México: Torres.

Scannone, J. C. (1999). Del símbolo a la práctica de la analogía. Stromata(55), 19 ss.

Scannone, J. C. (2003). Acontecimiento-sentido-acción. Aportaciones de Paul Ricoeur para una hermenéutica del acontecimiento y la acción histórica. Aplicación al acontecer argentino actual. Stromata, 273 ss.

Scannone, J. C. (2005). De más acá del símbolo a más allá de la práctica de la analogía. El lenguaje de la teología filosófica. En J. C. Scannone, Religión y nuevo pensamiento. Hacia una filosofía de la religión para nuestro tiempo desde América Latina, (pág. 187 ss). Barcelona: Ánthropos. 